\title{
The Impact of Industry 4.0 Implementation on Organizational Behavior and Corporate Culture: The Case of Pakistan's Retail Industry
}

\author{
Shahbaz Ali \\ School of Economics and Management, Xidian University, Xi'an, Shaanxi, China \\ E-mail: ali.shahbaz@qq.com \\ Yongping Xie \\ School of Economics and Management, Xidian University, Xi'an, Shaanxi, China
}

Received: 16 October 2020; Accepted: 25 November 2020; Published: 08 December 2020

\begin{abstract}
This paper measured the impact of the implementation of the five core Industry 4.0 technologies (artificial intelligence, big data analytics, cloud computing, cybersecurity, and Internet of Things (IoT)) on organizational behavior and corporate culture of businesses and organizations in Pakistan. Moreover, the influence of organizational behavior and corporate culture on organizational effectiveness was also analyzed in this paper. The retail industry of Pakistan was chosen as the subject of this study, and a quantitative approach, which included a questionnaire based on a five-point Likert scale ranging from "strongly agree" to "strongly disagree," was employed to gather the responses from participants, including both superiors and subordinates possessing the technological know-how of Industry 4.0. The findings indicated that the implementation of Industry 4.0 in Pakistan's retail sector helps positively transform organizational behavior and aids in building a great corporate culture. Moreover, it was found that both positive organizational behavior and great corporate culture help in improving the overall organizational effectiveness. This study took an unprecedented step to research Industry 4.0 from an organizational perspective. Furthermore, the carried-out study extended the theoretical body of knowledge by studying and examining the five crucial factors of Industry 4.0 that contribute to the service sector, particularly the retail industry, of the big emerging markets (BEM) economies, including Pakistan.
\end{abstract}

Index Terms: Industry 4.0, Organizational Behavior, Corporate Culture, Organizational Effectiveness, Pakistan’s Retail Industry

\section{Introduction}

The industrial sector plays a crucial part in uplifting the economy of a country. Technological change or technological development has gradually introduced some significant paradigm shifts in the industrial sector $[1,2]$. These paradigm shifts, in other words, are called "Industrial Revolutions." The industrial revolution is divided into four phases. The focus of the first industrial revolution was on mechanization, and both water and steam were used to power the factories. The second industrial revolution focused on mass production and electricity. Electronics, IT systems, and automation were the focus of the third industrial revolution. The fourth and current industrial revolution, which is more widely known as Industry 4.0, focuses on cyber-physical systems.

In recent years, researchers have become increasingly interested in Industry 4.0 due to its far-reaching influence [3-5]. Industry 4.0 utilizes various cutting-edge technologies, such as additive manufacturing, augmented reality, automation and industrial robots, big data analytics, blockchain, cloud computing, cyber-physical systems, cybersecurity, internet of data, internet of people, internet of service, IoT, semantic technologies, and simulation and modeling to completely reshape the value chain by transforming the process of carrying out a number of value chain activities, such as design, production, marketing, and distribution [6-11].

Most Industry 4.0 studies have focused mainly on the technological perspective of Industry 4.0, and these studies have tried to explore how Industry 4.0 impacts the manufacturing sector. However, remarkably few studies have been designed to provide the organizational perspective of Industry 4.0, and less attention has been paid to explore the impact of the implementation of Industry 4.0 on organizational behavior and corporate culture, which play a significant role in improving the overall organizational effectiveness. Furthermore, the existing research has failed to measure the impact of Industry 4.0 implementation on organizational effectiveness in the context of developing countries such as Pakistan. Industry 4.0 technologies alone cannot boost the effectiveness of organizations. Industry 4.0, therefore, should go hand in 
hand with organizational behavior and corporate culture to improve the overall organizational effectiveness.

Therefore, this study aimed to look at how Industry 4.0 implementation impacts organizational behavior and corporate culture of businesses and organizations in Pakistan. The objectives of the carried-out study are given as follows:

1. To measure the impact of the implementation of the five core Industry 4.0 technologies (artificial intelligence, big data analytics, cloud computing, cybersecurity, and IoT) on organizational behavior and corporate culture of businesses and organizations in Pakistan

2. To analyze the influence of organizational behavior and corporate culture on organizational effectiveness

The present study employed a quantitative approach that included a questionnaire based on a five-point Likert scale ranging from "strongly agree" to "strongly disagree." Participants in this study were selected from Pakistan's retail industry, the world's fastest-growing retail market, and witnessing a booming and impressive growth. However, to remain competitive in the global market, it is necessary to promote technological innovation within the industry; this can be achieved by implementing Industry 4.0 technologies in Pakistan's retail sector. The target population was composed of both superiors and subordinates, who possessed the technological know-how of Industry 4.0. The findings provide convincing evidence that the implementation of Industry 4.0 technologies in Pakistan's retail sector positively transforms organizational behavior and helps build a great corporate culture. Moreover, positive organizational behavior and great corporate culture lead to the improvement of the effectiveness of organizations.

The carried-out study is divided into five main sections. The first section provides brief background information, states the purpose of the carried-out study and the employed research approach, and provides the carried-out study's main findings. The second section provides a comprehensive literature review of Industry 4.0, organizational behavior, and corporate culture and states the present study's hypotheses. The third section provides comprehensive information on the research approach employed by this study. The fourth section shows the obtained results, and comprehensively discusses the results obtained by the carried-out study. The fifth and final section provides the information on principal conclusions, limitations of the carried-out study, and future recommendations.

\section{Literature Review}

\section{A. Industry 4.0}

Industry 4.0 is a broad term (initially coined by the German government in 2011) that refers to how technology, data acquisition, and automation evolve and come together to completely transform the way of carrying out various value chain activities, such as design, production, marketing, and distribution [12], [13]. While most of the research on Industry 4.0 has focused on how Industry 4.0 impacts the manufacturing sector, the influence of Industry 4.0 is far-reaching. Industry 4.0 has the potential to blend breakthroughs in business as a whole [5], [14], [15]. The focus of the first three industrial revolutions was primarily on technology advancement, whereas Industry 4.0 focuses more on how technology evolves and impacts everyday lives.

Although Industry 4.0 encompasses several enabling technologies, this study focuses on the five core pillars of Industry 4.0: (a) artificial intelligence, (b) big data analytics, (c) cloud computing, (d) cybersecurity, and (e) IoT. Fig. 1 shows the five core pillars of Industry 4.0.

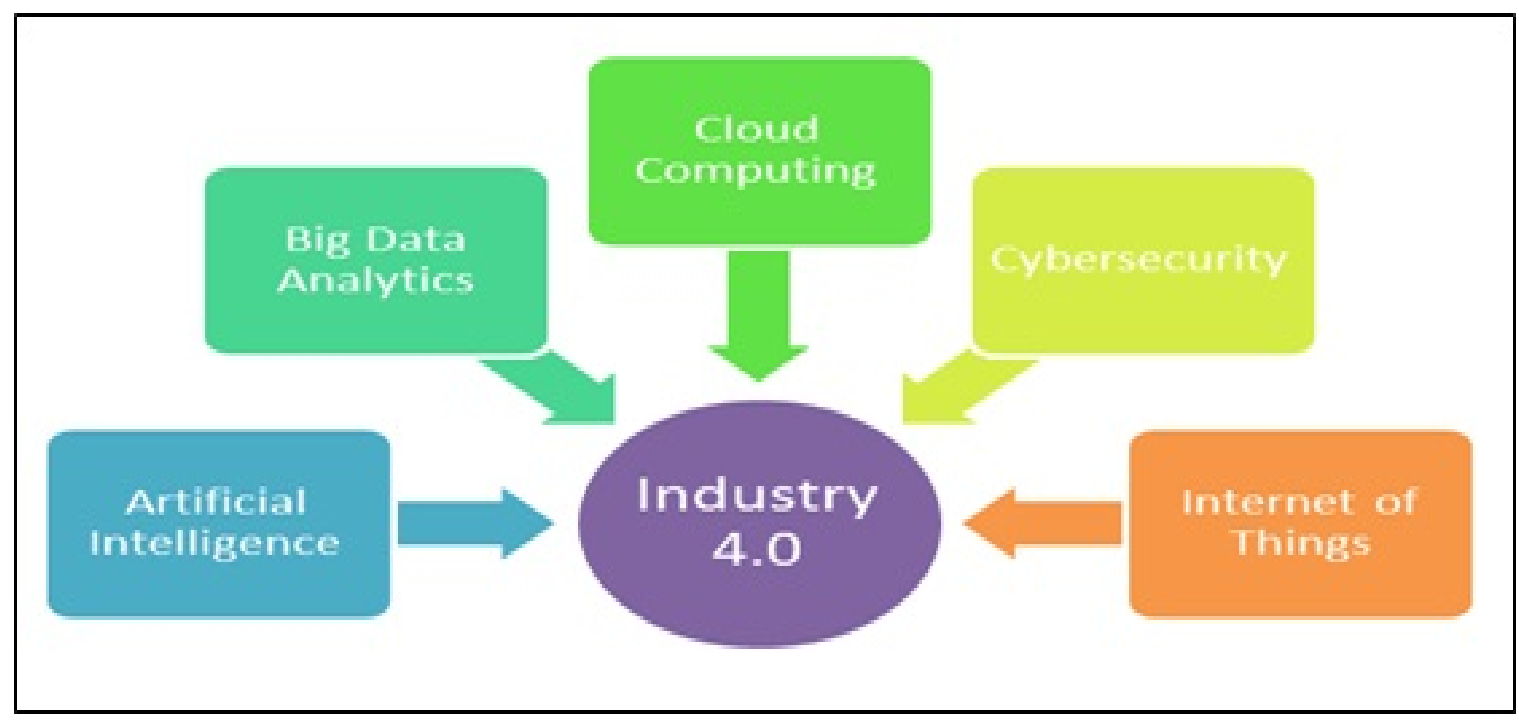

Fig. 1. Industry 4.0's Five Core Pillars 
Each of the core pillars is explained as follows:

\section{Artificial Intelligence}

There is now a substantial body of research on artificial intelligence. It is a broad term and encompasses several enabling technologies, such as machine learning, natural language processing, and deep learning, which helps in building intelligent machines that are capable of performing a variety of tasks ranging from sensing and comprehending to acting and learning $[16,17]$. Most researchers working in the area of artificial intelligence agree that artificial intelligence has completely transformed the way people interact with technology. Furthermore, artificial intelligence has added value to organizations.

In the context of Industry 4.0, several production processes are interconnected in a smart factory. Previous studies on artificial intelligence and Industry 4.0 have demonstrated that through artificial intelligence, machines can effectively learn, reproduce, and independently improve different processes [18, 19]. In other words, there is continuous communication among machines, interfaces, and components, and data in enormous amounts are collected, which ultimately helps industries in optimizing the manufacturing process, improving quality, designing better products, enhancing overall equipment effectiveness, driving efficiency, shortening design time, improving production reuse, reducing materials waste, performing predictive maintenance, and managing supply chains in a better way. For example, [20, 21] showed that the use of advanced artificial intelligence algorithms helps predict the failure of machines in an effective way. Furthermore, the subsequent failures can be predicted accurately with the help of deep and machine learning models. As a result, predictive maintenance leads to a significant reduction in unplanned outages and downtime. Industrial robotics is another application of artificial intelligence. According to [22, 23], robots, when used in an industrial environment, can use real-time environmental data to make independent decisions, which leads to the creations of a seamless blended process of humans and robots and the improvement of process efficiencies.

2. Big Data Analytics

Big data analytics refers to analyzing enormous data sets to find hidden patterns, insights, or trends that ultimately help make better and more informed business decisions [24]. Empirical evidence appears to confirm the notion that big data analytics helps both businesses and organizations in various ways, including a reduction in costs, improvement in operational efficiency, and increment in customer satisfaction and loyalty [25].

Big data analytics helps in improving several practices of Industry 4.0. Past studies have yielded some valuable insights into big data analytics' role in Industry 4.0. According to [26, 27], big data analytics plays a vital role in predictive manufacturing, where intelligent systems detect system failures and help find the root cause of the detected failures. Moreover, with artificial intelligence and big data analytics, intelligent systems can accurately detect subsequent failures. As a result, this helps businesses and organizations in improving overall production efficiency and enhancing operational transparency. The review of the literature shows that big data analytics leads to product quality improvement, waste reduction, cost reduction, and better management of both inventory and supply chains [28].

3. Cloud Computing

Cloud computing is an umbrella term that refers to using the internet to deliver various hosted services. With the help of this enabling technology, data can be exchanged in real-time, resulting in the building of a digital integration and collaboration based environment [29]. The existing literature demonstrates that cloud computing helps businesses and organizations adapt to digital transformation, which ultimately leads to improved productivity and quality [30-32].

Furthermore, cloud computing plays a vital role in the continual development of Industry 4.0. According to [16], cloud computing helps organizations exchange data throughout the organizations in real-time. Another application of cloud computing is in supply chain logistics. Cloud technology enables the supply chain to communicate with essential stockholders better and provides real-time visibility, which helps organizations manage the supply chain proactively and increase efficiency and improve risk management.

4. Cybersecurity

Cybersecurity is a broad term that refers to designing various practices, processes, and technologies, which serve the purpose of protecting several systems connected to the internet, including data, hardware, and software, from potential damage cyber-attack, or unauthorized access [33]. In the context of Industry 4.0, organizations connect themselves to the internet in real-time. On the one hand, this results in increased effectiveness and efficiency, but on the other hand, it introduces various cyber risks for the organizations.

Many scholars have stressed the importance of cybersecurity for organizations to remain competitive in the fourth industrial revolution era. They have suggested several practices to protect the systems from cyber-attacks, such as [34, 35]. In the existing literature on cybersecurity, there seems to be widespread agreement that organizations should make cybersecurity a fundamental part of their strategic processes, operations, and designs. Furthermore, cybersecurity should be placed at the start of any new initiative driven by Industry 4.0 .

5. IoT

A considerable amount of research has focused on IoT; it refers to the interconnection of machines that continuously communicate with each other and provide real-time data, which ultimately improves overall efficiency and effectiveness [36]. Empirical evidence has supported the claim that IoT enables organizations to efficiently use the available resources, which ultimately leads to an uplift in revenue. The existing literature provides several cases of the implementation of IoT in real life. The automotive industry is a common application area where IoT positively impacts the industry and helps 
organizations utilize their energy, time, and human resources effectively. Previous studies have shown that IoT plays a vital role in advancing diverse fields [37, 38].

\section{B. Organizational Behavior}

Organizational behavior refers to how individuals behave within an organizational setting and why they behave in a certain way within an organizational climate. Fred Luthans defined organizational behavior as "the understanding, prediction, and control of human behavior in organizations [39]." Organizational behavior talks about how both individuals and groups act and react toward one another and the organization as a whole and the impacts of these attitudes and actions on the organization's overall performance and functioning [40]. Many scholars have researched organizational behavior; they have acknowledged that the study of organizational behavior helps organizations create a healthy work environment, motivate ethical behavior, improve customer service and job performance, promote creativity and innovation, and encourage leadership [41, 42].

The existing literature categorizes organizational behavior into five important models: (a) autocratic model, (b) custodial model, (c) collegial model, (d) supportive model, and (e) system model. Each of the crucial models is briefly explained as follows:

\section{Autocratic Model}

The owners or managers of the organizations have the full power to make decisions and dictate their employees or subordinates in the autocratic model of organizational behavior. In this organizational behavior model, employees are bound to follow the orders of their superiors. The organizations that implement the autocratic model rarely offer any incentive or bonus to their employees; a paycheck is used in this environment as the reward system. The review of the literature shows that in the autocratic model, employees are generally loyal toward their superiors and not to the organization [43]. In the literature on the autocratic model of organizational behavior, there seems to be a general agreement that this model of organizational behavior leads to creating a fearful, insecure, and frustrated workforce, which ultimately results in unsatisfactory performance [44].

\section{Custodial Model}

The organizations that implement this model provide employees with some incentives, such as health-care and retirement plans. In this environment, the employees are loyal to the organization, not to the individual owners or managers. The existing literature on the custodial model of organizational behavior shows that employees feel secure in this environment. However, they do not collaborate actively due to the lack of strong encouragement [45, 46].

\section{Collegial Model}

The collegial model of organizational behavior seeks to develop a structure in which both superiors and subordinates work together as a team and focus on building healthy work relationships. In this environment, the superiors act like coaches, while employees act like members of a team. The coaches play an inspiring role and lead their teams to achieve organizational goals and objectives. Previous research has demonstrated that employees are loyal toward organizational goals in the collegial model and show a sense of responsibility. Moreover, employees feel obliged to create a positive organizational image [47, 48].

\section{Supportive Model}

The supportive model focuses on the inspiration and motivation of employees. It is generally agreed that continued support from superiors helps employees in improving their work performance. In this model, personal development opportunities are given to the employees; this ultimately helps employees accomplish organizational goals and objectives [49]. Furthermore, organizations following this model encourage employees to take initiatives.

\section{System Model}

The system model is the revolutionary model of organizational behavior that genuinely fosters a positive organizational culture. In this model, employees feel valued, and they realize their self-worth when working in this environment. Furthermore, they believe that the work they are performing has a purpose and meaning. Many studies have shown that implementing the system model helps organizations achieve their satisfaction and loyalty [50].

\section{Corporate Culture}

Numerous scholars have written extensively on corporate culture and have examined its role in organizational effectiveness. Corporate culture discusses the principles, attitudes, shared values, and philosophies that characterize organization members and define the organization's nature [51]. Previous studies have demonstrated that an organization's corporate culture has its roots in the structure, goals, approaches, and policies toward customers, employees, stakeholders, and the greater society [52-55].

The review of the literature shows that corporate culture can be categorized into four main types: (a) clan culture, (b) adhocracy culture, (c) market culture, and (d) hierarchy culture. Each of the main types is briefly explained as follows:

\section{Clan Culture}

Collaboration and friendliness are the focus of the clan culture. As the name suggests, the clan culture helps create a 
family-like environment where individuals perform work together and develop themselves by learning from the experienced ones. In the literature on clan culture, there seems to be a general agreement that clan culture helps build reliability, trust, and loyalty [56, 57].

\section{Adhocracy Culture}

The adhocracy culture focuses on creating a vibrant and innovative atmosphere where employees can take risks, make decisions, come up with better ideas, and implement those ideas for the betterment of the organization. In this environment, superiors play the role of inspirational innovators and continuously inspire and encourage the employees to bring innovation into the organization [57]. Previous studies have demonstrated that the adhocracy culture is oriented toward actions and significantly contributes to the change [58].

\section{Market Culture}

The market culture emphasizes competing effectively, achieving optimal results, and getting the work accomplished. As the name suggests, the market culture focuses on the market, and the organizations implementing this type of culture strive to make a considerable profit and capture the significant market share [57, 59].

\section{Hierarchy Culture}

The hierarchy culture is oriented toward procedures, processes, and systems. The review of the literature shows that the hierarchy culture pays significant attention to control and structure, and the organizations implementing this type of culture focus on creating stability and improving efficiency by accomplishing the work in the right way [60, 61].

\section{Industry 4.0: An Organizational Perspective}

Much of the debate over Industry 4.0 has revolved around how Industry 4.0 blends breakthroughs in the manufacturing industry. However, it is essential not to overlook that the implementation of Industry 4.0 technologies would significantly impact both businesses and organizations as a whole. A number of studies have supported the hypothesis that implementing new technologies in an organization has a significant impact on various aspects of the organization, such as organizational behavior and corporate culture. Recent research has tended to show that the organizations must carry out suitable managerial and organizational approaches to remain competitive, determined, and proactive in the era of the fourth industrial revolution, see for example [11,62, 63]. The review of the literature shows that implementing new technologies in businesses and organizations substantially influences cultures, management, and organizations. Therefore, it may be inferred that Industry 4.0 implementation would significantly impact how both individuals and groups act and react not only toward one another but also the organization as a whole. Moreover, the implementation of Industry 4.0 would significantly impact the principles, attitudes, shared values, and philosophies that help characterize organization members and define the organization's nature. All of these impacts would ultimately have a significant influence on organizational effectiveness. Thus, based on the existing literature on Industry 4.0, Organizational Behavior, and Corporate Culture, the carried-out study proposes the following hypotheses:

Hypothesis 1: Artificial Intelligence has a significant relationship with Organizational Behavior

Hypothesis 2: Big Data Analytics has a significant relationship with Organizational Behavior

Hypothesis 3: Cloud Computing has a significant relationship with Organizational Behavior

Hypothesis 4: Cybersecurity has a significant relationship with Organizational Behavior

Hypothesis 5: IoT has a significant relationship with Organizational Behavior

Hypothesis 6: Artificial Intelligence has a significant relationship with Corporate Culture

Hypothesis 7: Big Data Analytics has a significant relationship with Corporate Culture

Hypothesis 8: Cloud Computing has a significant relationship with Corporate Culture

Hypothesis 9: Cybersecurity has a significant relationship with Corporate Culture

Hypothesis 10: IoT has a significant relationship with Corporate Culture

Hypothesis 11: Organizational Behavior has a significant relationship with Organizational Effectiveness

Hypothesis 12: Corporate Culture has a significant relationship with Organizational Effectiveness

\section{Methodology}

\section{A. Sampling and Data Collection}

Participants in this study were selected from Pakistan's retail industry, the world's fastest-growing retail market, and witnessing a booming and impressive growth. However, to remain competitive in the global market, it is necessary to promote technological innovation within the industry; this can be achieved by implementing various Industry 4.0 technologies, such as artificial intelligence, big data analytics, cloud computing, and cybersecurity and IoT. The target population was composed of both superiors and subordinates, who possessed the technological know-how of Industry 4.0.

The data was collected through a questionnaire, which was distributed using online as well as offline methods, and a total of 270 responses were gathered from a sample of 316, out of which 18 responses were found invalid, so 252 responses were finally used, which is the adequate sample size for yielding valid results. 


\section{B. Research Instruments}

The present study employed a quantitative approach that included a questionnaire based on a five-point Likert scale ranging from "strongly agree" to "strongly disagree." The questionnaire was divided into nine sections: (a) respondents' demographics, (b) artificial intelligence, (c) big data analytics, (d) cloud computing, (e) cybersecurity, (f) IoT, (g) organizational behavior, (h) corporate culture, and (i) organizational effectiveness.

The demographics section included four items: (a) gender, (b) age, (c) highest education/degree achieved, and (d) work experience.

The artificial intelligence section was comprised of six items and asked questions, such as "artificial intelligence helps in enhancing customer satisfaction," "artificial intelligence helps in reducing customer complaints," "artificial intelligence influences both individual and group performance and activity within our organization," and "the innovative opportunities for the strategic usage of artificial intelligence, are continuously examined within our organization.”

The big data analytics section contained six items; the respondents were asked to answer questions, such as "we believe that big data analytics will play a significant role in shaping the future of our organization," "big data analytics helps in making better fact-based decisions," and "big data analytics helps in understanding both individual and group behavior within our organization."

The cloud computing section included six items, and the participants answered questions, such as "cloud computing helps in improving the way customer service is handled within our organization," "cloud computing allows for better communication and collaboration within our organizational settings," and "cloud computing brings a positive corporate culture transformation within our organization.”

The cybersecurity section was comprised of five items and asked questions, such as "enhanced cybersecurity and data protection approaches help in uplifting revenue," "we believe that cybersecurity will play a significant role in shaping the future of our organization," and "our organization continuously empowers us with information through a variety of information security awareness programs."

The IoT section contained five items; the respondents were asked to answer questions, such as "IoT helps in increasing efficiency and productivity" and "IoT connects all equipment to the Internet and performs real-time analytics, which helps understand the customers in a better way."

The organizational behavior section included ten items, and the participants answered questions, such as "our organization has a strong focus on customer service and satisfaction," "my current morale in my job is good," "I have trust and confidence in the leadership of my organization," "managers communicate a clear sense of direction within our organization," "there is a strong feeling of teamwork and collaboration within our organization," and "I understand how my job contributes to the overall success of our organization.”

The corporate culture section was comprised of six items and asked questions, such as "my work is respected," "I am a happy employee of our organization," "I have all the support that I need to do my job properly," and "I get the opportunity to grow and learn new things."

The organizational effectiveness section contained ten items; the respondents were asked to answer questions, such as "all employees are treated equally, regardless of age or gender," "our organization conducts business ethically, honestly, and fairly," "men, as well as women, have the same opportunity for growth," and "I feel empowered to take initiatives and make decisions about my work."

\section{Results and Discussion}

\section{A. Reliability and Validity Analysis}

The data analysis process was conducted using IBM SPSS Statistics Version 26. The reliability of the measurement model was tested using Cronbach's Alpha, whereas Pearson product-moment Correlation was used to test the validity of the measurement model. The results of reliability and validity tests are presented in Table 1.

It is generally agreed that for an acceptable internal consistency, the value of Cronbach's Alpha should at least be 0.7. The obtained results show that the value of Cronbach's Alpha for each variable in the measurement model was higher than 0.7 ( 0.871 being the lowest, whereas 0.962 being the highest). Therefore, the reliability test was successfully passed by the measurement model. In order to pass the validity test based on the Pearson Product-Moment Correlation, the measurement model should satisfy two conditions: (a) the p-Value should be lower than 0.01 (when the correlation is significant at the 0.01 level (2-tailed)) and (b) the value of Pearson Correlation should be higher than the critical value for Pearson's $\mathrm{r}$. According to the table of critical values for Pearson's r, for a sample of 252 and a p-Value of 0.01 (2-tailed), the critical value of Pearson's $r$ should be 0.161994 . It can be inferred from the obtained results that each variable in the measurement model satisfied both conditions: the p-Value for each variable in the measurement model was lower than 0.01 , and the value of Pearson Correlation for each variable in the measurement model was higher than 0.161994 (0.613 being the lowest, whereas 0.903 being the highest). Hence, the measurement model also passed the validity test. The obtained results, therefore, conclude that the measurement model was proved both valid and reliable. 
Table 1. Reliability and Validity Test Results

\begin{tabular}{|c|c|c|c|c|c|}
\hline \multirow{2}{*}{ Variables } & \multirow{2}{*}{ No. of Items } & \multirow{2}{*}{ Cronbach's $\alpha$} & \multicolumn{3}{|c|}{ Pearson Product-Moment Correlation } \\
\cline { 4 - 6 } & & & Pearson Correlation & Sig. (2-tailed) & N \\
\hline Artificial Intelligence & 6 & 0.871 & $0.752^{* *}$ & 0.000 & 252 \\
\hline Big Data Analytics & 6 & 0.905 & $0.613^{* *}$ & 0.000 & 252 \\
\hline Cloud Computing & 6 & 0.874 & $0.888^{* *}$ & 0.000 & 252 \\
\hline Cybersecurity & 5 & 0.900 & $0.816^{* *}$ & 0.000 & 252 \\
\hline Internet of Things & 5 & 0.908 & $0.903^{* *}$ & 0.000 & 252 \\
\hline Organizational Behavior & 10 & 0.962 & $0.885^{* *}$ & 0.000 & 252 \\
\hline Corporate Culture & 6 & 0.958 & $0.773^{* *}$ & 0.000 & 252 \\
\hline Organizational Effectiveness & 10 & 0.940 & $0.808^{* *}$ & 0.000 & 252 \\
\hline
\end{tabular}

** Correlation is significant at the 0.01 level (2-tailed)

\section{B. Correlation and Regression Analysis}

The correlation analysis was carried-out to evaluate the co-relationship among all variables in the measurement model. Table 2 shows the obtained results of the correlation analysis.

Table 2. Correlation Analysis Results

\begin{tabular}{|c|c|c|c|c|c|c|c|c|}
\hline \multicolumn{9}{|c|}{ Correlations } \\
\hline & $\begin{array}{c}\text { Artificial } \\
\text { Intelligence }\end{array}$ & $\begin{array}{l}\text { Big Data } \\
\text { Analytics }\end{array}$ & $\begin{array}{c}\text { Cloud } \\
\text { Computing }\end{array}$ & Cybersecurity & $\begin{array}{c}\text { Internet } \\
\text { of } \\
\text { Things }\end{array}$ & $\begin{array}{l}\text { Organizational } \\
\text { Behavior }\end{array}$ & $\begin{array}{l}\text { Corporate } \\
\text { Culture }\end{array}$ & $\begin{array}{l}\text { Organizational } \\
\text { Effectiveness }\end{array}$ \\
\hline $\begin{array}{c}\text { Artificial } \\
\text { Intelligence }\end{array}$ & 1 & & & & & & & \\
\hline $\begin{array}{l}\text { Big Data } \\
\text { Analytics }\end{array}$ & $0.860^{* *}$ & 1 & & & & & & \\
\hline $\begin{array}{c}\text { Cloud } \\
\text { Computing }\end{array}$ & $0.673^{* *}$ & $0.760^{* *}$ & 1 & & & & & \\
\hline Cybersecurity & $0.421^{* *}$ & $0.492^{* *}$ & $0.710^{* *}$ & 1 & & & & \\
\hline $\begin{array}{c}\text { Internet of } \\
\text { Things }\end{array}$ & $0.420^{* *}$ & $0.508^{* *}$ & $0.806^{* *}$ & $0.901^{* *}$ & 1 & & & \\
\hline $\begin{array}{c}\text { Organizational } \\
\text { Behavior }\end{array}$ & $0.806^{* *}$ & $0.759^{* *}$ & $0.701^{* *}$ & $0.593^{* *}$ & $0.531^{* *}$ & 1 & & \\
\hline $\begin{array}{c}\text { Corporate } \\
\text { Culture }\end{array}$ & $0.738^{* *}$ & $0.734^{* *}$ & $0.511^{* *}$ & $0.409^{* *}$ & $0.445^{* *}$ & $0.838^{* *}$ & 1 & \\
\hline $\begin{array}{l}\text { Organizational } \\
\text { Effectiveness }\end{array}$ & $0.649^{* *}$ & $0.757^{* *}$ & $0.699^{* *}$ & $0.621^{* *}$ & $0.581^{* *}$ & $0.826^{* *}$ & $0.804^{* *}$ & 1 \\
\hline
\end{tabular}

** Correlation is significant at the 0.01 level (2-tailed)

As shown in Table 2, positive and statistically significant correlations were obtained among the five core pillars of Industry 4.0 (artificial intelligence, big data analytics, cloud computing, cybersecurity, and IoT), organizational behavior, and corporate culture. Furthermore, correlations among organizational behavior, corporate culture, and organizational effectiveness were positive and statistically significant. Therefore, it can be inferred from the obtained results that all variables in the measurement model were both positively and significantly correlated with each other. Hence, the obtained results were found suitable for carrying out the regression analysis.

In order to test the proposed hypotheses, the regression analysis was carried out in three steps. First, the regression analysis was carried out among the five core pillars of Industry 4.0 (artificial intelligence, big data analytics, cloud computing, cybersecurity, and IoT) and organizational behavior. Artificial intelligence, big data analytics, cloud computing, cybersecurity, and IoT were considered independent variables, whereas organizational behavior was considered the dependent variable. The obtained results of the regression analysis are reported in Table 3 . 
Table 3. Regression (Organizational Behavior) Analysis Results

\begin{tabular}{|c|c|c|c|c|c|c|}
\hline \multicolumn{7}{|c|}{ Regressions (Organizational Behavior) } \\
\hline & $\mathbf{R}$ & $\mathbf{R}^{\mathbf{2}}$ & Adjusted $^{\mathbf{2}}$ & $\boldsymbol{\beta}$ & $\mathbf{t}$ & Sig. \\
\hline Artificial Intelligence & 0.806 & 0.650 & 0.649 & 0.806 & 21.553 & 0.000 \\
\hline Big Data Analytics & 0.759 & 0.576 & 0.574 & 0.759 & 18.433 & 0.000 \\
\hline Cloud Computing & 0.701 & 0.491 & 0.489 & 0.701 & 15.528 & 0.000 \\
\hline Cybersecurity & 0.593 & 0.351 & 0.349 & 0.593 & 11.639 & 0.000 \\
\hline Internet of Things & 0.531 & 0.282 & 0.279 & 0.531 & 9.913 & 0.000 \\
\hline
\end{tabular}

The findings indicate that artificial intelligence was positively and significantly correlated with organizational behavior, and total variance of $65 \%$ in organizational behavior was explained by artificial intelligence. Furthermore, the beta coefficient was positive and statistically significant and had a t-Value of 21.553 and a p-Value of 0.000 ; hence, Hypothesis 1 was accepted.

A positive and statistically significant correlation was obtained between big data analytics and organizational behavior, and big data analytics explained a total variance of $57.6 \%$ in organizational behavior. Besides, the obtained beta coefficient was positive and statistically significant and had a t-Value of 18.433 and a p-Value of 0.000 , so Hypothesis 2 was not rejected.

The correlation between cloud computing and organizational behavior was positive and statistically significant, and total variance of $49.1 \%$ in organizational behavior was explained by cloud computing. Additionally, the beta coefficient was positive and statistically significant and had a t-Value of 15.528 and a p-Value of 0.000; hence, Hypothesis 3 was accepted.

Cybersecurity was positively and significantly correlated with organizational behavior, and cybersecurity explained a total variance of $35.1 \%$ in organizational behavior. Furthermore, the obtained beta coefficient was positive and statistically significant and had a t-Value of 11.639 and a p-Value of 0.000, so Hypothesis 4 was not rejected.

A positive and statistically significant correlation was obtained between IoT and organizational behavior, and IoT explained a total variance of $28.2 \%$ in organizational behavior. Besides, the beta coefficient was positive and statistically significant and had a t-Value of 9.913 and a p-Value of 0.000; hence, Hypothesis 5 was accepted.

Second, the regression analysis was carried out among the five core pillars of Industry 4.0 (artificial intelligence, big data analytics, cloud computing, cybersecurity, and IoT) and corporate culture. Artificial intelligence, big data analytics, cloud computing, cybersecurity, and IoT were considered independent variables, whereas corporate culture was considered the dependent variable. Table 4 presents the obtained results of the regression analysis.

Table 4. Regression (Corporate Culture) Analysis Results

\begin{tabular}{|c|c|c|c|c|c|c|}
\hline \multicolumn{7}{|c|}{ Regressions (Corporate Culture) } \\
\hline & $\mathbf{R}$ & $\mathbf{R}^{\mathbf{2}}$ & Adjusted R $^{2}$ & $\boldsymbol{\beta}$ & $\mathbf{t}$ & Sig. \\
\hline Artificial Intelligence & 0.738 & 0.544 & 0.542 & 0.738 & 17.274 & 0.000 \\
\hline Big Data Analytics & 0.734 & 0.539 & 0.538 & 0.734 & 17.112 & 0.000 \\
\hline Cloud Computing & 0.511 & 0.261 & 0.258 & 0.511 & 9.398 & 0.000 \\
\hline Cybersecurity & 0.409 & 0.167 & 0.164 & 0.409 & 7.084 & 0.000 \\
\hline Internet of Things & 0.445 & 0.198 & 0.194 & 0.445 & 7.847 & 0.000 \\
\hline
\end{tabular}

It can be seen from Table 4 that a positive and statistically significant correlation was obtained between artificial intelligence and corporate culture, and total variance of 55.4\% in corporate culture was explained by artificial intelligence. Besides, the beta coefficient was positive and statistically significant and had a t-Value of 17.274 and a p-Value of 0.000 , so Hypothesis 6 was accepted.

Big data analytics was positively and significantly correlated with corporate culture, and big data analytics explained a total variance of $53.9 \%$ in corporate culture. Furthermore, the obtained beta coefficient was positive and statistically significant and had a t-Value of 17.112 and a p-Value of 0.000; hence, Hypothesis 7 was not rejected.

The correlation between cloud computing and corporate culture was positive and statistically significant, and total variance of $26.1 \%$ in corporate culture was explained by cloud computing. Additionally, the beta coefficient was positive and statistically significant and had a t-Value of 9.398 and a p-Value of 0.000, so Hypothesis 8 was accepted.

A positive and statistically significant correlation was obtained between cybersecurity and corporate culture, and cybersecurity explained a total variance of $16.7 \%$ in corporate culture. Besides, the obtained beta coefficient was positive and statistically significant and had a t-Value of 7.084 and a p-Value of 0.000; hence, Hypothesis 9 was not rejected.

IoT was positively and significantly correlated with corporate culture, and IoT explained a total variance of $19.8 \%$ in corporate culture. Furthermore, the beta coefficient was positive and statistically significant and had a t-Value of 7.847 and a p-Value of 0.000 , so Hypothesis 10 was accepted.

Third, the regression analysis was carried-out among organizational behavior, corporate culture, and organizational effectiveness. Organizational behavior and corporate culture were considered independent variables, whereas organizational effectiveness was considered the dependent variable. The obtained results of the regression analysis are 
shown in Table 5.

Table 5. Regression (Organizational Effectiveness) Analysis Results

\begin{tabular}{|c|c|c|c|c|c|c|}
\hline \multicolumn{7}{|c|}{ Regressions (Organizational Effectiveness) } \\
\hline & $\mathbf{R}$ & $\mathbf{R}^{\mathbf{2}}$ & Adjusted R $^{\mathbf{2}}$ & $\boldsymbol{\beta}$ & $\mathbf{T}$ & Sig. \\
\hline Organizational Behavior & 0.826 & 0.682 & 0.681 & 0.826 & 23.180 & 0.000 \\
\hline Corporate Culture & 0.804 & 0.646 & 0.645 & 0.804 & 21.375 & 0.000 \\
\hline
\end{tabular}

As shown in Table 5, organizational behavior was positively and significantly correlated with organizational effectiveness, and total variance of $68.2 \%$ in organizational effectiveness was explained by organizational behavior. Furthermore, the beta coefficient was positive and statistically significant and had a t-Value of 23.180 and a p-Value of 0.000; hence, Hypothesis 11 was accepted.

A positive and statistically significant correlation was obtained between corporate culture and organizational effectiveness, and corporate culture explained a total variance of $64.6 \%$ in organizational effectiveness. Besides, the obtained beta coefficient was positive and statistically significant and had a t-Value of 21.375 and a p-Value of 0.000 , so Hypothesis 12 was not rejected.

The present study was carried out to measure the impact of implementing the five core Industry 4.0 technologies (artificial intelligence, big data analytics, cloud computing, cybersecurity, and IoT) on organizational behavior and corporate culture from a developing country perspective. Furthermore, the present study analyzed the influence of organizational behavior and corporate culture on organizational effectiveness. Pakistan's retail industry, the world's fastest-growing retail market, was chosen as the subject of this study. The obtained results yield some interesting findings and provide convincing evidence in favor of Industry 4.0 implementation in Pakistan's retail sector.

The present study's findings indicate a positive and statistically significant relationship between artificial intelligence and organizational behavior. Furthermore, the relationship between artificial intelligence and corporate culture was positive and statistically significant. Therefore, it can be concluded that the better implementation of artificial intelligence will positively transform both organizational behavior and corporate culture.

The relationship between big data analytics and organizational behavior was positive and statistically significant. Besides, there was a positive and statistically significant relationship between big data analytics and corporate culture; this indicates that organizational behavior and corporate culture will be fostered positively if the implementation of big data analytics is encouraged by businesses and organizations.

There was a positive and statistically significant relationship between cloud computing and organizational behavior. Additionally, the relationship between cloud computing and corporate culture was positive and statistically significant; this means that boosting cloud computing implementation will help affect organizational behavior positively and aid in building a great corporate culture.

The relationship between cybersecurity and organizational behavior was positive and statistically significant. Furthermore, there was a positive and statistically significant relationship between cybersecurity and corporate culture. Therefore, it can be inferred that positively supporting the implementation of cybersecurity and data protection approaches will lead to the positive transformation of organizational behavior and corporate culture.

There was a positive and statistically significant relationship between IoT and organizational behavior. Besides, the relationship between IoT and corporate culture was positive and statistically significant; this indicates that the better implementation of IoT by businesses and organizations will positively reshape organizational behavior and corporate culture.

Finally, the influence of organizational behavior and corporate culture on organizational effectiveness was analyzed. The obtained results show that the relationship between organizational behavior and organizational effectiveness was positive and statistically significant. Additionally, there was a positive and statistically significant relationship between corporate culture and organizational effectiveness. Therefore, it can be inferred that a positive transformation in organizational behavior and corporate culture will help improve organizational effectiveness.

\section{Conclusions}

The present study thoroughly looked at how Industry 4.0 impacts organizational behavior and corporate culture of businesses and organizations in developing countries such as Pakistan. Furthermore, the carried-out study analyzed the influence of both organizational behavior and corporate culture on organizational effectiveness. A quantitative approach, which included a questionnaire, was employed by the present study to gather the participants' responses (including both superiors and subordinates) belonging to Pakistan's retail industry.

The findings provide convincing evidence that the implementation of Industry 4.0 technologies, especially artificial intelligence, big data analytics, cloud computing, cybersecurity, and IoT, in Pakistan's retail sector positively transforms organizational behavior and helps build a great corporate culture. Moreover, positive organizational behavior and great corporate culture lead to the improvement of the effectiveness of organizations. Therefore, it is reasonable to conclude that Pakistan's retail sector should positively encourage the implementation of Industry 4.0 technologies, especially the technologies mentioned above, to boost the overall organizational effectiveness. 
However, the findings of the carried-out study are not generalizable to all sectors of the country's economy. Future research will have to compare and contrast the organizations' overall effectiveness before and after the implementation of Industry 4.0 technologies; this will help assess the extent to which Industry 4.0 implementation impacts both businesses and organizations in developing countries such as Pakistan. Furthermore, future studies will have to continue to explore the impact of Industry 4.0 implementation on different sectors of the economy from an organizational perspective; this will ultimately help further our understanding of Industry 4.0.

\section{Acknowledgements}

This research received funding from National Natural Science Foundation: Research on Core Enterprise Leadership and Mechanism of Its Role in Strategic Alliance of Technological Innovation (71472144), Research on the Influence Mechanism of Core Enterprise Leadership on the Performance of Technology Innovation Strategy Alliance (14XJA630004) of the Western and Frontier Regions Project of the Humanities Society of the Ministry of Education, Research on Xi'an Civil-Military Integration Industry Cluster Development Based on the Core Enterprise Leading the Xi'an Comprehensive Innovation and Reform Experiment of Xi'an Soft Science Project of Xi'an Science and Technology Plan [2017110SF/RK004-(6)]. The project Research on Development Path of Shaanxi Civil-Military Integration Industrial Cluster (2019KRM006) is co-funded by the Soft Science Research Program of Shaanxi Province.

\section{References}

[1] P. N. Stearns, The industrial revolution in world history. Routledge, 2018.

[2] R. S. Cowan, “The "Industrial Revolution” in the home: household technology and social change in the twentieth century," in The Routledge Companion to Modernity, Space and Gender, 1st ed., Routledge, 2018, pp. 81-97.

[3] Lele, "Industry 4.0,” in Disruptive Technologies for the Militaries and Security, Singapore: Springer, 2019, pp. $205-215$.

[4] S. Vaidya, P. Ambad, and S. Bhosle, “Industry 4.0-a glimpse,” Procedia Manuf., vol. 20, pp. 233-238, 2018.

[5] V. Roblek, M. Meško, and A. Krapež, “A complex view of Industry 4.0,” Sage Open, vol. 6, no. 2, 2016.

[6] D. Ibarra, J. Ganzarain, and J. I. Igartua, “Business model innovation through Industry 4.0: A review,” Procedia Manuf., vol. 22 , pp. 4-10, 2018.

[7] S. S. Kamble, A. Gunasekaran, and S. A. Gawankar, "Sustainable Industry 4.0 framework: A systematic literature review identifying the current trends and future perspectives,” Process Saf. Environ. Prot., vol. 117, pp. 408-425, 2018.

[8] Y. Liao, F. Deschamps, E. de F. R. Loures, and L. F. P. Ramos, "Past, present and future of Industry 4.0-a systematic literature review and research agenda proposal,” Int. J. Prod. Res., vol. 55, no. 12, pp. 3609-3629, 2017.

[9] E. Negri, L. Fumagalli, and M. Macchi, “A review of the roles of digital twin in cps-based production systems,” Procedia Manuf., vol. 11, pp. 939-948, 2017.

[10] C. Pereira and F. Romero, “A review of the meanings and the implications of the Industry 4.0 concept,” Procedia Manuf., vol. 13, pp. 1206-1214, 2017.

[11] M. Piccarozzi, B. Aquilani, and C. Gatti, "Industry 4.0 in management studies: A systematic literature review,” Sustainability, vol. 10, no. 10, p. 3821, 2018.

[12] L. S. Dalenogare, G. B. Benitez, N. F. Ayala, and A. G. Frank, "The expected contribution of Industry 4.0 technologies for industrial performance,” Int. J. Prod. Econ., vol. 204, pp. 383-394, 2018.

[13] M. Imran, W. U. Hameed, and A. U. Haque, "Influence of Industry 4.0 on the Production and Service Sectors in Pakistan: Evidence from Textile and Logistics Industries,” Soc. Sci., vol. 7, no. 12, p. 246, 2018.

[14] L. Li, “China's manufacturing locus in 2025: With a comparison of 'Made-in-China 2025' and 'Industry 4.0,'” Technol. Forecast. Soc. Change, vol. 135, pp. 66-74, 2018.

[15] J. M. Müller, D. Kiel, and K.-I. Voigt, "What drives the implementation of Industry 4.0? The role of opportunities and challenges in the context of sustainability," Sustainability, vol. 10, no. 1, p. 247, 2017.

[16] J. Wan, J. Yang, Z. Wang, and Q. Hua, “Artificial intelligence for cloud-assisted smart factory,” IEEE Access, vol. 6, pp. 55419-55430, 2018.

[17] P. Zheng et al., "Smart manufacturing systems for Industry 4.0: Conceptual framework, scenarios, and future perspectives," Front. Mech. Eng., vol. 13, no. 2, pp. 137-150, 2018.

[18] B. Li, B. Hou, W. Yu, X. Lu, and C. Yang, “Applications of artificial intelligence in intelligent manufacturing: a review,” Front. Inf. Technol. Electron. Eng., vol. 18, no. 1, pp. 86-96, 2017.

[19] V. Terziyan, S. Gryshko, and M. Golovianko, "Patented intelligence: Cloning human decision models for Industry 4.0,” J. Manuf. Syst., vol. 48, pp. 204-217, 2018.

[20] S. Suman, S. Z. Khan, S. K. Das, and S. K. Chand, "Slope stability analysis using artificial intelligence techniques," Nat. Hazards, vol. 84, no. 2, pp. 727-748, 2016.

[21] S. Zhang, C. Liu, S. Su, Y. Han, and X. Li, “A feature extraction method for predictive maintenance with time - lagged correlation - based curve - registration model,” Int. J. Netw. Manag., vol. 28, no. 5, p. e2025, 2018.

[22] H. Yang, C. Baradat, S. Krut, and F. Pierrot, “An agile manufacturing system for large workspace applications,” Int. J. Adv. Manuf. Technol., vol. 85, no. 1-4, pp. 25-35, 2016.

[23] P. Alhama Blanco, F. Abu-Dakka, and M. Abderrahim, "Practical use of robot manipulators as intelligent manufacturing systems," Sensors, vol. 18, no. 9, p. 2877, 2018.

[24] R. Dubey, A. Gunasekaran, S. J. Childe, S. F. Wamba, and T. Papadopoulos, “The impact of big data on world-class sustainable manufacturing,” Int. J. Adv. Manuf. Technol., vol. 84, no. 1-4, pp. 631-645, 2016. 
[25] G. Li, J. Tan, and S. S. Chaudhry, “Industry 4.0 and big data innovations,” Enterp. Inf. Syst., vol. 13, no. 2, pp. 145-147, 2018.

[26] J. Yan, Y. Meng, L. Lu, and L. Li, "Industrial big data in an Industry 4.0 environment: Challenges, schemes, and applications for predictive maintenance,” IEEE Access, vol. 5, pp. 23484-23491, 2017.

[27] J. Wan et al., "A manufacturing big data solution for active preventive maintenance,” IEEE Trans. Ind. Informatics, vol. 13, no. 4, pp. 2039-2047, 2017.

[28] J. Woo, S.-J. Shin, W. Seo, and P. Meilanitasari, "Developing a big data analytics platform for manufacturing systems: architecture, method, and implementation,” Int. J. Adv. Manuf. Technol., vol. 99, no. 9-12, pp. 2193-2217, 2018.

[29] D. Georgakopoulos, P. P. Jayaraman, M. Fazia, M. Villari, and R. Ranjan, "IoT and edge cloud computing roadmap for manufacturing,” IEEE Cloud Comput., vol. 4, pp. 66-73, 2016.

[30] M. Aazam, S. Zeadally, and K. A. Harras, “Deploying fog computing in industrial IoT and Industry 4.0,” IEEE Trans. Ind. Informatics, vol. 14, no. 10, pp. 4674-4682, 2018.

[31] J. He, G. Jia, G. Han, H. Wang, and X. Yang, "Locality-aware replacement algorithm in flash memory to optimize cloud computing for smart factory of Industry 4.0,” IEEE Access, vol. 5, pp. 16252-16262, 2017.

[32] K.-B. Ooi, V.-H. Lee, G. W.-H. Tan, T.-S. Hew, and J.-J. Hew, "Cloud computing in manufacturing: The next industrial revolution in Malaysia?,” Expert Syst. Appl., vol. 93, pp. 376-394, 2018.

[33] M. Lezzi, M. Lazoi, and A. Corallo, “Cybersecurity for Industry 4.0 in the current literature: A reference framework,” Comput. Ind., vol. 103, pp. 97-110, 2018.

[34] T. M. Fernández-Caramés and P. Fraga-Lamas, "A Review on the Application of Blockchain to the Next Generation of Cybersecure Industry 4.0 Smart Factories,” IEEE Access, vol. 7, pp. 45201-45218, 2019.

[35] P. Fraga-Lamas and T. M. Fernández-Caramés, "A review on blockchain technologies for an advanced and cyber-resilient automotive industry,” IEEE Access, vol. 7, pp. 17578-17598, 2019.

[36] L. Da Xu, E. L. Xu, and L. Li, “Industry 4.0: state of the art and future trends,” Int. J. Prod. Res., vol. 56, no. 8, pp. 2941-2962, 2018.

[37] J. Trappey, C. V. Trappey, C.-Y. Fan, A. P. Hsu, X.-K. Li, and I. J. Lee, "IoT patent roadmap for smart logistic service provision in the context of Industry 4.0,” J. Chinese Inst. Eng., vol. 40, no. 7, pp. 593-602, 2017.

[38] J. Trappey, C. V. Trappey, U. H. Govindarajan, A. C. Chuang, and J. J. Sun, "A review of essential standards and patent landscapes for the IoT: A key enabler for Industry 4.0,” Adv. Eng. Informatics, vol. 33, pp. 208-229, 2017.

[39] F. Luthans, Organizational Behavior, 12th ed. McGraw-Hill Education, 2010.

[40] D. Miscenko and D. V. Day, “Identity and identification at work,” Organ. Psychol. Rev., vol. 6, no. 3, pp. 215-247, 2015.

[41] Y. Li, Q. C. Yujie Lu, and Y. Han, "Organizational Behavior in Megaprojects: Integrative Review and Directions for Future Research,” J. Manag. Eng., vol. 35, no. 4, 2019.

[42] T. A. Norton, S. L. Parker, H. Zacher, and N. M. Ashkanasy, "Employee green behavior: A theoretical framework, multilevel review, and future research agenda,” Organ. Environ., vol. 28, no. 1, pp. 103-125, 2015.

[43] H. De Hoogh, L. L. Greer, and D. N. Den Hartog, "Diabolical dictators or capable commanders? An investigation of the differential effects of autocratic leadership on team performance,” Leadersh. Q., vol. 26, no. 5, pp. 687-701, 2015.

[44] Nayak and B. B. Mishra, "Impact of leadership style on organizational effectiveness," Manag. Labour Stud., vol. 30, no. 1, pp. 90-103, 2005.

[45] P. Ramluggun, "A critical exploration of the management of self-harm in a male custodial setting: Qualitative findings of a comparative analysis of prison staff views on self-harm,” J. Forensic Nurs., vol. 9, no. 1, pp. 23-34, 2013.

[46] L. D. Burgio and K. L. Burgio, "Institutional staff training and management: A review of the literature and a model for geriatric, long-term-care facilities,” Int. J. Aging Hum. Dev., vol. 30, no. 4, pp. 287-302, 1990.

[47] E. McGrath, H. D. Cooper - Thomas, E. Garrosa, A. I. Sanz - Vergel, and G. W. Cheung, “Rested, friendly, and engaged: The role of daily positive collegial interactions at work,” J. Organ. Behav., vol. 38, no. 8, pp. 1213 - 1226, 2017.

[48] L. Shrifian, "Collegial management to improve the effectiveness of managers, organizational behavior in educational institutions,” Procedia-Social Behav. Sci., vol. 29, pp. 1169-1178, 2011.

[49] M. Tremblay, M.-C. Gaudet, and C. Vandenberghe, "The role of group-level perceived organizational support and collective affective commitment in the relationship between leaders' directive and supportive behaviors and group-level helping behaviors,” Pers. Rev., vol. 48, no. 2, pp. 417-437, 2019.

[50] T. M. Amabile, “A model of creativity and innovation in organizations,” Res. Organ. Behav., vol. 10, no. 1, pp. 123-167, 1988.

[51] J. Dempsey, “Moral responsibility, shared values, and corporate culture,” Bus. Ethics Q., vol. 25, no. 3, pp. 319-340, 2015.

[52] K. Kanagaretnam, Z. Xiu, and Z. Zhou, “Does Culture Matter for Corporate Philanthropic Giving?,” Emerg. Mark. Financ. Trade, vol. 55, no. 10, pp. 2365-2387, 2019.

[53] S. M. Adnan, D. Hay, and C. J. van Staden, "The influence of culture and corporate governance on corporate social responsibility disclosure: A cross country analysis,” J. Clean. Prod., vol. 198, pp. 820-832, 2018.

[54] M. Sugita and T. Takahashi, "Influence of corporate culture on environmental management performance: An empirical study of japanese firms,” Corp. Soc. Responsib. Environ. Manag., vol. 22, no. 3, pp. 182-192, 2015.

[55] E. Ucar, “Local creative culture and corporate innovation,” J. Bus. Res., vol. 91, pp. 60-70, 2018.

[56] H. Kim, "Transformational leadership, organizational clan culture, organizational affective commitment, and organizational citizenship behavior: A case of South Korea’s public sector,” Public Organ. Rev., vol. 14, no. 3, pp. 397-417, 2014.

[57] M. Tharp, “Four organizational culture types,” Hawort Organ. Cult. White Pap., 2009.

[58] A. Hartnell, A. Y. Ou, and A. Kinicki, "Organizational culture and organizational effectiveness: A meta-analytic investigation of the competing values framework’s theoretical suppositions,” J. Appl. Psychol., vol. 96, no. 4, p. 677, 2011.

[59] S. Tsui, H. Wang, and K. R. Xin, “Organizational culture in China: An analysis of culture dimensions and culture types,” Manag. Organ. Rev., vol. 2, no. 3, pp. 345-376, 2006.

[60] B. Lund, “Organizational culture and job satisfaction,” J. Bus. Ind. Mark., vol. 18, no. 3, pp. 219-236, 2003.

[61] P. A. Gambrel and R. Cianci, “Maslow’s hierarchy of needs: Does it apply in a collectivist culture,” J. Appl. Manag. Entrep., vol. 8, no. 2, p. 143, 2003. 
[62] H. Mohelska and M. Sokolova, "Management approaches for Industry 4.0-the organizational culture perspective,” Technol. Econ. Dev. Econ., vol. 24, no. 6, pp. 2225-2240, 2018.

[63] S. Shamim, S. Cang, H. Yu, and Y. Li, "Management approaches for Industry 4.0: A human resource management perspective,” in IEEE Congress on Evolutionary Computation (CEC), 2016, pp. 5309-5316.

\section{Authors' Profiles}

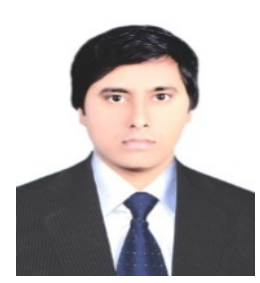

Shahbaz Ali received his B.E. in Electrical (Telecommunications) from Sukkur Institute of Business Administration, Pakistan in 2014. He is currently pursuing an MBA in Corporate Management from Xidian University, China. His research interests are in Technology and Innovation Management.

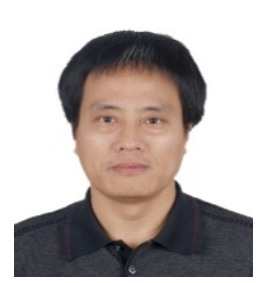

Yongping Xie is currently working as an Associate Professor in the School of Economics and Management, Xidian University, China. He received his B.S. in Automatic and Control Engineering from Nanjing University of Science and Technology, China in 1994, M.S. in Business Management from Xidian University, China in 2003, and Ph.D. in Management Science and Engineering from Xi'an University of Technology, China in 2013. His research interests are in Technology Innovation and Strategic Management.

How to cite this paper: Shahbaz Ali, Yongping Xie, " The Impact of Industry 4.0 Implementation on Organizational Behavior and Corporate Culture: The Case of Pakistan's Retail Industry ", International Journal of Engineering and Manufacturing (IJEM), Vol.10, No.6, pp.20-31, 2020. DOI: 10.5815/ijem.2020.06.03 